\title{
How Does Personalization in News Stories Influence Intentions to Help With Drought? Assessing the Influence of State Empathy and Its Antecedents
}

\section{OPEN ACCESS}

Edited by:

lan Holman,

Cranfield University, United Kingdom

Reviewed by:

Emma Frances Bloomfield,

University of Nevada, Las Vegas,

United States

Sibo Chen,

Ryerson University, Canada

Lindsey Jo McEwen,

University of the West of England,

United Kingdom

*Correspondence:

Dara M. Wald

dwald@iastate.edu

Specialty section:

This article was submitted to

Science and Environmental

Communication,

a section of the journal

Frontiers in Communication

Received: 31 July 2020 Accepted: 16 November 2020

Published: 24 February 2021

Citation:

Wald DM, Johnston EW, Wellman N and Harlow J (2021) How Does Personalization in News Stories

Influence Intentions to Help With Drought? Assessing the Influence of State Empathy and Its Antecedents.

Front. Commun. 5:588978. doi: 10.3389/fcomm.2020.588978

\section{Dara M. Wald ${ }^{1 *}$, Erik W. Johnston ${ }^{2}$, Ned Wellman ${ }^{3}$ and John Harlow ${ }^{4}$}

\begin{abstract}
1 Greenlee School of Journalism and Communication, lowa State University, Ames, IA, United States, ${ }^{2}$ School for the Future of Innovation in Society and School of Complex Adaptive Systems, Arizona State University, Tempe, AZ, United States, ${ }^{3}$ W.P. Carey School of Business, Arizona State University, Tempe, AZ, United States, ${ }^{4}$ Engagement Lab, Emerson College, Boston, MA, United States
\end{abstract}

Personalized stories are a powerful tool for communicating about science, particularly when a scientific topic is complex or unfamiliar. One example of such a topic is drought, something many regions of the world face regularly. Like other environmental challenges, drought recovery efforts benefit from a mobilized collective response through prosocial action, including volunteering and donations. The objective of this study was to examine how storytelling about drought influences emotional responses and empathic processes that in turn contribute to prosocial action. Using data collected from an online survey $(N=249)$ with undergraduate students, the current study tests the hypothesis that, relative to non-personalized stories, personalized news stories about drought will increase audiences' cognitive and emotional responses, including perceived suffering, narrative engagement, and state empathy. In addition, this study examines how emotional responses to personalized news stories influence readers' intentions to donate to farmers suffering from drought. Results reveal that personalized news stories are more likely than non-personalized stories to increase readers' state empathy and perceptions of others' suffering. Perceived suffering was directly related to the affective and cognitive dimensions of state empathy. Narrative engagement (i.e., transportation) was also directly related to the affective and cognitive dimensions of state empathy and indirectly associated with intentions to donate to assist those suffering from drought. Affective state empathy was directly associated with donation intentions, suggesting that an emotional response to media portrayals of suffering may promote prosocial intentions. We discuss the potential implications for using personalized news stories about drought and other natural disasters to motivate prosocial action.

Keywords: trait empathy, altruism, prosocial behavior, emotions, identification, affective news 


\section{INTRODUCTION}

News media are a key source of public information about natural hazards and natural disasters such as drought (Wilson, 2000; Houston et al., 2012). Droughts, defined as prolonged periods with rainfall below normal recorded levels ${ }^{1}$, are associated with reduced water supply, poor water quality, diminished crop yields, elevated food and energy prices, wildfires, impaired riparian habitats, and deteriorated rangeland (Mishra and Singh, 2010; Church et al., 2020). Droughts are ubiquitous, occurring in most countries and climatic zones (Wilhite et al., 2014). The cumulated cost of drought in the United States make it, in economic terms, the costliest recurring natural disaster (Cook et al., 2007). The negative social, environmental, and economic effects of drought are "further aggravated by growing demand for water" and earth's increasing mean surface temperature due to climate change (Mishra and Singh, 2010, p. 205). The public looks to news outlets for information about natural hazards, including what areas are affected, the consequences of the hazard, and community response efforts.

Until recently, environmental news has generally adhered to the doctrine of "just-the-facts" reporting, often de-emphasizing the role of emotions. Yet a growing number of scholars have criticized this approach to reporting, suggesting that emotional storytelling is a critical tool to engage audiences and encourage public action around social and environmental crises (Papacharissi and de Fatima Oliveira, 2012; Swim and Bloodhart, 2015; Beckett and Deuze, 2016; Maier et al., 2017) and large-scale distant disasters (Solman and Henderson, 2019). Reporting about natural disasters often features people in crisis or emotional images of people suffering (Solman and Henderson, 2019). Indeed, the emotional focus of news media's coverage of disasters has been described as an important tool for arousing compassionate responses from readers, which in turn may mobilize public engagement, volunteering, and other forms of prosocial action (Joye, 2015).

Emotional storytelling is characterized by the frequent use of dramatic and personalized narratives (Wahl-Jorgensen, 2013). As a form of strategic narrative, personalized narratives focus on individual experiences, rather than collective or group experiences (Zhou and Niederdeppe, 2017). Extensive scholarship in health communication has documented the persuasive effect of personalized news stories and their potential limitations (Green, 2006; Kreuter et al., 2007; Kim et al., 2012; Zhou and Niederdeppe, 2017). While mass media coverage of science and biological topics regularly includes personalized stories (Dahlstrom, 2014), little is currently known about the implications of including personalized storytelling in news coverage of natural hazards such as drought and water scarcity. The potential for more frequent and severe natural hazards associated with climate change highlights the importance of understanding how personalized stories engage readers and may contribute to public action during environmental crises.

\footnotetext{
${ }^{1}$ Definitions of drought vary widely. An overview of the definitions is beyond the scope of this paper, but see Mishra and Singh (2010) for a detailed review.
}

Wahl-Jorgensen (2013) suggests that personalized storytelling can trigger an emotional reaction in readers that is "an indispensable prerequisite of political action (Boltanski, 1999)" (p. 132). Thus, when the goal of communication is to motivate action, personalized storytelling may be key (Maier et al., 2017). Yet to date, the links between exposure to personalized news stories about natural hazards, the arousal of empathy, and action to support hazard recovery or mitigation efforts are far from clear. The present study explores audiences' responses to both personalized and non-personalized news stories about drought conditions in the Western U.S. Using an online experiment ( $N$ $=249$ ), this study tests the hypotheses that personalization will increase audiences' perceptions of others' suffering, narrative engagement (i.e., transportation into the story), state empathy, and ultimately, intentions to donate money to those affected by drought. Additionally, this study seeks to identify the specific pathways contributing to the arousal of the cognitive, affective, and associative dimensions of empathy, and intentions to support farmers affected by drought.

\section{THEORETICAL BACKGROUND}

\section{Narratives and Personalization}

Narratives are generally defined as a story about an event or a chain of events that occur over some time period to an individual or group of characters (Dahlstrom, 2014). Narratives can entertain or be strategically employed to promote social or individual action (Zhou and Niederdeppe, 2017). Broadly, compared to informational formats, narratives evoke a greater emotional response, including empathic concern (Shen et al., 2014), and help audiences identify with specific characters or contexts (Murphy et al., 2013; Dahlstrom, 2014).

Situated within the domain of strategic narratives, personalized stories are characterized by a focus on individual experiences, feelings, and perspectives (Zhou and Niederdeppe, 2017). Personalization has received a great deal of attention in the field of communication, particularly in the context of persuasive health communication. Prior work in this area has suggested that personalized news focused on characters' perspectives and feelings can promote behavior change. For example, stories focused on individuals' experiences produced significantly greater positive emotions, empathic attitudes, intentions, and behaviors toward stigmatized groups than non-narrative formats (Oliver et al., 2012). Messages targeting respondents' identities were more effective than information-based messages about organ donation, contributing to greater donor registration rates (Dillow and Weber, 2016). Though scholarship on personalized news about natural disasters is more limited, Maier et al. (2017) found that the use of personalized stories about large-scale distant suffering due to mass violence in Africa was more effective than non-personalized news. Personalization was also more effective than including photographs, mobilizing information, or statistical information in generating emotional responses similar to empathy (e.g., sympathy, sadness, anger, compassion) and, indirectly, charitable giving (Maier et al., 2017). 
Understanding how to mobilize coordinated community response efforts is crucial considering the role that the public can play in hazard response, recovery efforts, and political action to encourage policies that mitigate the negative socioeconomic impacts of drought and water scarcity. The objective of this study is to examine the effects of personalized and nonpersonalized stories about drought to improve our understanding of how and when personalization can motivative emotional responses and prosocial action to support individuals suffering from drought. To do so, we apply Zhou and Niederdeppe's (2017) conceptualization of personalized narratives as stories that include (1) identifiable individuals, (2) individual experiences (i.e., rather than collective or shared experiences), and (3) an expression of the character's perspectives and emotions. Below we describe three theoretical constructs often described as critical antecedents of narrative persuasion-empathy, perceived suffering, and transportation. We then review theories and previous research examining the association between empathy and prosocial action. Finally, we the describe the results of an online survey assessing the effect of personalization on readers' cognitive and emotional responses, narrative engagement, and intentions to donate to farmers suffering from drought.

\section{Empathy}

There is growing attention in journalism and communication studies to the use of emotive storytelling in arousing sympathy (Maier et al., 2017) and empathy (Shen et al., 2014). Empathy is a multi-item contrast, that some argue differs substantially from emotions such as sympathy and pity (Gerdes et al., 2010). Definitions of empathy vary widely across disciplines. Communication researchers describe empathy as being either trait-based (e.g., an enduring characteristic of an individual) or state-based (e.g., a reaction to empathy-arousing messages; see Shen, 2010a). State-based empathy (or state empathy) is a construct that describes "actual automatic and somatic responses" (Preston and de Waal, 2002, p. 4) that are activated after exposure to specific media stimuli (Shen, 2010a).

State empathy is a process that includes physiological and intellectual dimensions, though scholars disagree about what to call these dimensions (Shen, 2010a). Using Shen's previous framework, we define state empathy as a multi-item construct composed of a physiological dimension (labeled as "affective"), an intellectual dimension (labeled as "cognitive"), and an associative dimension (called "associative"). The affective dimension of state empathy includes the observer's ability to physically mirror the experiences or feelings of others (Iacoboni, 2008). Cognitive state empathy is generally defined and measured as perspective taking, or the act of picturing oneself in another's shoes. The associative dimension is a measure of character identification, often as a result of perceived similarities between the audience and the message subject. The role of associative state empathy has received less attention than the other dimensions, contributing to questions about whether identification, due to perceived similarities between the audience and the message subject, can reliably generate an empathic response. Thus, we add to the existing body of literature by simultaneously evaluating the effect of personalized news stories on the cognitive, affective, and associative dimensions of state empathy.
Contemporary scholarship has developed interventions focused on both the affective (Decety and Jackson, 2006) and cognitive dimensions of state empathy, including efforts to induce perspective taking for people with AIDS, minority groups, and the homeless (Batson et al., 1997b; Stephan and Finlay, 1999; Finlay and Stephan, 2000). State empathy has been measured after exposing participants to media stimuli, such as pictures, videos, or audio recordings of harmful acts toward people or animals (Shelton and Rogers, 1981; Batson et al., 1997a,b, 2002; Schultz, 2000; Berenguer, 2007; Swim and Bloodhart, 2015), or after exposure to public service announcements (PSAs) (Stiff et al., 1988; Bagozzi and Moore, 1994; Finlay and Stephan, 2000; Campbell and Babrow, 2004; Shen, 2010a,b, 2011; Shen et al., 2014). Exposure to personalized narratives, including a newspaper account of someone else's emotional or physical experience, has also been used to arouse empathic responses (Stiff et al., 1988; Shen et al., 2014), though this format has received less attention than PSAs. Drawing on this work we posit that:

H1: Personalized news stories (vs. non-personalized news stories) will be positively associated with readers' state empathy.

\section{Media Coverage and Perceived Suffering}

Most people experience natural disasters through media coverage (Maier et al., 2017). Therefore, how the story is framed and the frequency of the media coverage can influence public perceptions of natural hazards. Indeed, frequent local-level newspaper coverage of drought conditions in California was significantly associated with greater public concerns about drought (Duffy, 2016).

To date, there is limited scholarship exploring media coverage of slow-onset hazards. However, a recent review of news coverage about the California drought found that news stories focused on slow-onset hazards (such as drought) are generally confined to episodic frames and focused on socio-economic impacts (Duffy, 2016). Episodic frames about hazards generally focus on individual suffering and impacts. Media representations of hazards that focus on suffering have the potential to arouse intense emotional responses (Aarøe, 2011). The emotional emphasis of media coverage of slow-onset hazards has been criticized for exaggerating risk and sensationalizing serious concerns, which can create problems for recovery efforts. Despite concerns about the use of dramatic narrative stories to boost readership, Solman and Henderson (2019) suggest that disaster reporting "is one of the few legitimate places for emotional expression in news journalism" (p. 1642).

Scholars who have examined the use of emotive storytelling in disaster reporting have suggested that news focused on others' suffering may carry more weight than reports focused on property damage or the severity of the disaster, and are more effective at capturing media attention and mobilizing public action (Joye, 2015; Solman and Henderson, 2019). Indeed, personalized stories about large-scale distant suffering heightened readers' emotional distress more than stories focused on statistical information or stories including photographs of victims (Maier et al., 2017). Yet previous work in this area has 
primarily focused on readers' emotional distress, not readers' perceptions of others' suffering. According to (Decety and Lamm, 2006), a prerequisite for communication and empathy arousal is the preservation of individuality. While making a link between the self and other though perspective taking is a critically important component of empathy, separating our own feelings from others' feelings and thoughts, or self-other awareness, is also essential to preventing ecocentric responses to others' feelings and thoughts (Segal et al., 2017). Therefore, this study will also examine how personalized news stories impact readers' perceptions of others' suffering and whether these perceptions are associated with state empathy.

H2: Personalized news stories (vs. non-personalized news stories) will be positively associated with readers' perceived suffering.

H3: Perceived suffering will be positively associated with readers' state empathy.

\section{Narrative Engagement}

Narrative engagement, also called absorption, is a popular umbrella concept used to describe a readers' immersion into the story world (Oliver et al., 2012; Appel et al., 2015). Transportation is a subtype of narrative engagement described as a psychological state that simultaneously involves attention, imagery, and emotions (Appel et al., 2015). Transportation relates to the experience of engaging with, or being transported into a narrative world (Green et al., 2004). Previous work has reported mixed results regarding the relationship between transportation and empathy. Oliver et al. (2012) found that story involvement, a subtheme in Green and Brock (2000) narrative transportation scale, influenced emotional reactions to a narrative news story and intentions to help stigmatized groups (prisoners and elderly persons). Transportation was a significant predictor of empathy arousal in response to a narrative but not a significant mediator of narrative impact on empathy and cognitive responses (Shen et al., 2014). Drawing on this work, we propose the following hypotheses:

H4: Personalized news stories (vs. non-personalized news stories) will be positively associated with readers' transportation into the story.

H5: Transportation will be positively associated with perceived suffering and state empathy.

\section{The Empathy-Altruism Hypothesis}

Much of the scholarship on empathy is grounded in the empathyaltruism hypothesis (Batson, 1991). Batson and colleagues (see Batson et al., 1989, for a review) tested this hypothesis through a series of experiments exploring the relationship between empathic feelings (e.g., sympathy, compassion, warmth, tenderness, etc.), positive attitudes toward others (Batson et al., 1997b; Finlay and Stephan, 2000), and behavioral intentions (Batson et al., 2002). Results indicate that participants prompted to imagine the subject's feelings (compared to those prompted to concentrate on being objective) were significantly more likely to express intentions to donate funds to support an addiction and counseling service (Batson et al., 2002).
Following Batson's work, empathy is regularly described as a key factor in social interaction (Gerdes and Segal, 2009), civic engagement (Miaskiewicz and Monarchi, 2008), and social tolerance (Segal et al., 2012). Indeed, researchers in the fields of psychology, social work, and business have identified empathy as a critical source of prosocial behavior (Grant and Berry, 2011; Segal et al., 2017; Batson, 2018), often defined as voluntary actions benefiting others or society (Eisenberg and Miller, 1987). Bagozzi and Moore (1994) exposed respondents to a "rational" appeal condition and an emotional appeal (called the highempathy condition) and found that respondents in the latter group expressed greater intentions to help victims of child abuse. Participants reported greater distress and willingness to contribute to an organization that helps children with cancer when they were exposed to a stimulus with an identified victim rather than a non-identified victim (Kogut and Ritov, 2005). Guided by research in the tradition of the theory of reasoned action (Ajzen, 1991; Kim and Hunter, 1993), Oliver et al. (2012) found that empathic attitudes were associated with stronger intentions to help stigmatized groups dealing with healthrelated challenges.

As the examples above illustrate, most of the previous work considering the role of empathy-arousing messages in communication has focused on the health domain (e.g., Stiff et al., 1988; Shen, 2010a,b, 2011). There is also a substantial body of work in environmental contexts focused on arousing empathy for animals (Shelton and Rogers, 1981; Schultz, 2000; Berenguer, 2007, 2010) and assessing the relationships between empathy, pro-environmental attitudes, and pro-environmental behavior. For example, Swim and Bloodhart (2015) exposed participants to messages focused on climate change-related threats to polar bears, and found that participants prompted to take the perspective of the animals were more likely (than those prompted to remain objective) to donate to environmental advocacy organizations. Here, we expand this work by focusing on the impacts of drought-though this context has implications for climate change communication and messages about other natural hazards and disasters. Drawing on the empathy-altruism hypothesis and previous work in health and environmental contexts, we posit the following:

H6. State empathy will be positively associated with intentions to donate to farmers suffering from drought.

\section{Assessing the Cognitive, Affective, and Associative Dimensions of Empathy as a Source of Prosocial Behavior}

Early scholars debated whether empathy-driven prosocial action occurred in response to others' affective cues-as Hoffman (1981) posited-or as a result of a cognitive process driven by individuals' perspective taking abilities (Decety and Jackson, 2006). Proponents of the "affective assumption" have suggested that narratives generate an emotional involvement with characters (Slater and Rouner, 2002; Green et al., 2004; Busselle and Bilandzic, 2009) and that it is the emotional response to others' needs that produces the "other-oriented desire" to reduce perceived distress or suffering (Davis, 1994, p. 134). 
Indeed, experimental research across a variety of contexts has found a strong association between readers' emotional responses (i.e., distress) and willingness to help victims in need (Kogut and Ritov, 2005; Maier et al., 2017).

There is also evidence to support the association between the cognitive dimensions of empathy, including perspective taking, and prosocial behavior-or the "cognitive hypothesis." Perspective taking has been associated with increased psychological closeness between individuals, helping behavior (Cialdini et al., 1997), and mimicking behavior (van Baaren et al., 2009; Müller et al., 2012).

Still, other scholars have suggested that the cognitive and affective dimensions are "sequentially and causally connected" (Stiff et al., 1988, p. 200) such that cognition enables people to take the perspectives of others, but it is affective empathy that generates the motivation to act. Keen (2010) has suggested that the affective, cognitive, and associative dimensions are complementary, especially in response to reading, because "When texts invite readers to feel, they also stimulate readers' thinking" (p. 69).

Others have suggested that identification, a key component of the associative dimension of state empathy, is critical for communication and behavior because: "you persuade a man [sic] only insofar as you can talk his language by speech, gesture, tonality, order, image, attitude, idea, identifying your ways with his" (Burke, 1969, p. 55). Thus, a character's identity, gender, socio-demographic characteristics, along with their expressed values may generate associative state empathy when they align with readers' values and identity. Identification is the process through which relationships develop and social bonding occurs (Shen, 2010a,b) and is necessary for message relevance (Campbell and Babrow, 2004) and reduced reactance, which can lead to the rejection of persuasive messages (Shen, 2010a). Shen (2010a) has suggested that identification is associated with Kelman's theory of attitude change and may therefore be, "more predictive of behavior" than the other dimensions of state empathy.

To date, scholarship on empathy in communication regularly treats the multi-item construct of state empathy as a single outcome variable, limiting current understanding of the underlying mechanisms associated with empathy arousal and helping behavior in response to narrative news stories. Indeed, we are not familiar with any study to date that has tested a tripartite model of state empathy, as proposed here. To address this gap, we use a structural equation model to simultaneously test the effect of the cognitive, affective, and associative dimensions of state empathy on prosocial behavior, asking the following research question:

RQ1: To what extent do the cognitive, affective, and associative dimensions of state empathy influence intentions to donate to others?

\section{METHODS}

\section{Stimuli}

Data were collected using online surveys through the Qualtrics platform. The survey took $15 \mathrm{~min}$ to complete. Participants were assigned randomly to one condition (personalized or nonpersonalized). Both conditions included a simulated news story about drought conditions in the Southwestern U.S. in 2015 (Personalized $=392$ words; Non-personalized $=387$ words). Both stories were titled, "Arizona farmers burdened by the Megadrought" and formatted to resemble an AP-style article. We included a single image of drought conditions across the state of California from 2011 to 2015. The image came from the U.S. Drought Monitor and did not vary across conditions. We kept the introductory paragraph and the structure of the article the same across both stories to prevent the introduction of confounding cues. The articles were based on reports by the Associated Press and designed to avoid specific partisan cues. Both news stories are available in the Supplementary Material.

The focus of the articles in the two conditions differed. The personalized story included three components of personalized narratives: (1) an identifiable farmer, (2) direct quotes about the farmer's experience with drought, and (3) direct quotes about the farmer's economic and personal suffering due to drought conditions. The non-personalized story focused primarily on expert concern about the 2015 drought. It broadly addressed the social and economic impacts of drought conditions for farmers in the Southwest, though it did not include any direct quotes from individual farmers or descriptions of the character's emotional state or experiences.

The survey for this study began with an assessment of participants' trait empathy. Trait empathy refers an individual's unique ability to respond to another person's distress while state empathy is situation based. Following previous scholarship, we include trait empathy as a control variable likely associated with state responses to a stimulus (Bagozzi and Moore, 1994; Finlay and Stephan, 2000; Campbell and Babrow, 2004; Shen, 2010a,b; Shen, 2011; Shen et al., 2014). After completing the trait measures, participants read one of the two randomly assigned stories, rated their perceptions of the story, completed the perceived suffering, state empathy, and transportation measures, and intentions to donate to farmers affected by drought in the Southwest. Finally, participants completed demographic questions.

\section{Participants}

Eleven participants dropped out of the study before they could complete the survey and were removed from the data, resulting in a sample size of $N=249$. Participants were undergraduate students enrolled in an introductory course on mass communication at a public university in the midwestern United States ( $M$ age $=20$ years, $S D=1.4$ years). We distributed surveys in a classroom setting and provided participants extra credit for participation. Most respondents were women (67\%) who had completed some college $(M=2.73$ and $S D=0.68)$ and self-reported as moderately wealthy growing up $(1=$ poor to 5 $=$ wealthy; $M=3.2, S D=0.90)$, with income in the range of $\$ 50,000$ to $\$ 99,000(1=$ less than $\$ 10,000$ to $9=$ over $\$ 150,000$; $M=6.35, S D=2.13$ ). While we didn't ask for information about race, the student population at this University is $70 \%$ white (Data USA, n.d.). 


\begin{tabular}{|c|c|c|c|}
\hline & \multicolumn{3}{|c|}{ Factor } \\
\hline & Cognitive SE & Affective SE & Associative SE \\
\hline & 1 & 2 & 3 \\
\hline I can understand the points of view expressed in the article & 0.809 & 0.121 & 0.084 \\
\hline I recognize the situation detailed in the article & 0.781 & 0.045 & 0.136 \\
\hline Reactions to the drought are understandable & 0.642 & 0.133 & 0.127 \\
\hline The emotions expressed in this story are genuine & 0.576 & 0.316 & 0.041 \\
\hline I can understand what farmers in the southwest are going through & 0.589 & 0.286 & 0.292 \\
\hline I experienced the same emotions as the farmer(s) when reading this story & 0.202 & 0.803 & 0.368 \\
\hline I was in a similar emotional state as the farmer(s) when reading the story & 0.148 & 0.776 & 0.421 \\
\hline I can feel the farmer's emotions & 0.310 & 0.704 & 0.258 \\
\hline When reading the message, I was fully absorbed & 0.230 & 0.510 & 0.410 \\
\hline I can identify with the farmers in the story & 0.210 & 0.370 & 0.800 \\
\hline I can identify with the situation described in the story & 0.145 & 0.236 & 0.770 \\
\hline I can relate to what farmers are going through in the story & 0.146 & 0.449 & 0.688 \\
\hline
\end{tabular}

Values above the cutoff criteria of 0.5 are indicated in boldface.

In our sample, 62 participants had a single missing value, resulting in a small portion $(0.44 \%)$ of the total number of missing values over the total number of responses across all participants. Preliminary tests were conducted in SPSS 26 (IBM). For all analysis $p<0.05$ was considered significant. Scale reliability was measured using Cronbach's alpha $>0.65$ was considered acceptable (Nunnally, 1978). ${ }^{2}$

\section{Measurements}

State empathy was measured using a previously validated scale (Shen, 2011). The scale included 12 items representing the affective, cognitive, and associative dimensions of state empathy and ranged from $1=$ not at all to $5=$ completely. Principal-axis factoring with varimax rotation identified a three-factor solution explaining $64 \%$ of the variance in state empathy (Factor scores and items listed in Table 1). The first factor labeled "cognitive" was associated with five statements pertaining to the reader's understanding of others' point of view and recognition of the situation detailed in the articles $(M=3.61, S D=0.70$, Cronbach's alpha $=0.84)$. The second factor, which we labeled "affective" was associated with four statements related to readers' emotional reactions to the story $(M=3.07, S D=0.94$, Cronbach's alpha $=0.89$ ). The final factor we labeled "associative," and it was comprised of three statements about identifying with the topic and individual experiences detailed in the stories $(M=2.97, S D$ $=1.02$, Cronbach's alpha $=0.88$ ). In the following sections, we refer to these as cognitive SE, affective SE, and associative SE.

Perceived suffering was measured using three items asking participants to indicate whether the story portrayed the pain, suffering and distress associated with drought in the Southwest (from $1=$ strongly disagree to $5=$ strongly agree). The three items created a reliable scale and were collapsed $(M=3.51, S D=0.87$, Cronbach's alpha $=0.89$ ).

\footnotetext{
${ }^{2}$ State empathy items with a factor loading of 0.50 or greater were retained (Matsunaga, 2010).
}

Transportation into the story was assessed using Appel et al.'s (2015) Transportation Scale - Short Form. The fiveitem items had seven-point response scales (from $1=$ not at all $)$ to $7=$ very much $)$ and were reliable $(M=4.07, S D=$ 1.32 , Cronbach's alpha $=0.90)$.

Intentions to donate were measured after reading the newspaper articles. Participants read the following statement: "Lots of things come up that keep people from donating to social organizations even if they want to." Respondents then answered the question: "Would you be willing to donate money to help farmers in the Southwest affected by the drought?" by selecting one of two possible options: $0=$ no, $1=$ yes.

Trait empathy was measured using the affective and cognitive dimensions of the Social Empathy Index (SEI) (Gerdes et al., 2011; Segal et al., 2012). The full SEI includes 22 items measuring five dimensions of empathy and responses range from $1=$ never to $6=$ always. The scale included 9 items measuring the affective dimensions of trait empathy $(M=4.53, S D=0.67$, Chronbach's alpha $=0.83$ ). Example questions included: "When I see someone receive a gift that makes them happy, I feel happy myself," "I am good at understanding other people's emotions." And "When I see someone being publicly embarrassed, I cringe a little." One item was removed to improve scale reliability ("When I see someone accidentally hit his or her thumb with a hammer, I feel a flash of pain myself”).

\section{Analysis}

The theoretical model was tested in Mplus 8 using structural equation modeling (SEM) in Muthén and Muthén (1998-2017). We used the WLSMV estimator, recommended for models with categorical outcome variables. The chi-square value reported below is calculated using the DIFFTEST function in Mplus. Trait empathy was placed in the model as a control on state empathy. Story personalization $(0=$ non-personalized; $1=$ personalized $)$ was an exogenous variable that influenced all of the other posttest variables in the model: perceived suffering, state empathy and prosocial intentions. 
TABLE 2 | Correlations.

\begin{tabular}{|c|c|c|c|c|c|c|}
\hline & 1. Cog. SE & 2. Aff. SE & 3. Assoc. SE & 4. Per. Suffering & 5. Transport & 6. Int. to Donate \\
\hline 1. Cog. SE & 1.00 & & & & & \\
\hline 2. Aff. SE & $0.519^{\star \star}$ & 1.00 & & & & \\
\hline 3. Assoc. SE & $0.496^{\star \star}$ & $0.751^{\star \star}$ & 1.00 & & & \\
\hline 4. Per. Suffering & $0.612^{\star *}$ & $0.567^{\star \star}$ & $0.429^{\star *}$ & 1.00 & & \\
\hline 5. Transport & $0.579^{\star \star}$ & $0.721^{\star \star}$ & $0.601^{\star \star}$ & $0.567^{\star \star}$ & 1.00 & \\
\hline 6. Int. to Donate & $0.263^{\star \star}$ & $0.232^{\star \star}$ & 0.105 & $0.207^{\star \star}$ & $0.170^{*}$ & 1.00 \\
\hline
\end{tabular}

${ }^{\star} p<0.05 .{ }^{* *} p<0.01$.

TABLE 3 | Descriptive statistics for non-personalized and personalized stories.

\begin{tabular}{llllll}
\hline & \multicolumn{3}{c}{ Story format } \\
\cline { 2 - 3 } & \multicolumn{2}{c}{ Non-personalized } & & \multicolumn{2}{c}{ Personalized } \\
\cline { 2 - 3 } \cline { 5 - 6 } & $\mathbf{M}$ & SD & & $\mathbf{M}$ & SD \\
\hline Cog. SE & 3.46 & 0.70 & & 3.75 & 0.67 \\
Aff. SE & 2.89 & 0.93 & & 3.23 & 0.91 \\
Assoc. SE & 2.89 & 1.00 & & 3.05 & 1.04 \\
Per. Suffering & 3.37 & 0.92 & & 3.65 & 0.79 \\
Transport & 3.94 & 1.36 & & 4.19 & 1.26 \\
Int. to Donate & 0.42 & 0.49 & & 0.44 & 0.49 \\
\hline
\end{tabular}

Model fit was evaluated using the comparative fit index (CFI), standardized root-mean-square residual (SRMR), and rootmean-square error of approximation (RMSEA) criteria identified by $\mathrm{Hu}$ and Bentler (1999): CFI $>0.90$ and RMSEA $<0.05$. We adopted a $95 \%$ confidence model in the bootstrapping procedure. All exogenous variables were correlated.

\section{RESULTS}

Because this research concerned both the impact of story type on behavioral intentions and the mediating role of state empathy, perceived suffering, and transportation, we followed O'Keefe's (2003) suggestion and did not conduct a message manipulation check as the messages differed on objective, modifiable features. We used a structural equation model to evaluate the direct and indirect effects of personification on state empathy, perceived suffering, transportation, and intentions to donate.

\section{Preliminary Analysis}

Correlations between key variables are presented in Table 2. To address H1, H2, and H4, we conducted ANOVA tests to evaluate the main effects of personalization on state empathy (SE), perceived suffering, and transportation. Descriptive results are reported in Table 3. There were significant treatment group effects on cognitive SE $F_{(1,246)}=11.73, p<0.001$ and affective SE $F_{(1,246)}=8.54, p<0.01$. Respondents' scores on perceived suffering also varied significantly between the personalized and non-personalized story versions $F_{(1,247)}=6.72, p<0.01$. These findings provide support for $\mathrm{H} 1$ (i.e., personalization is associated with state empathy) and $\mathrm{H} 2$ (i.e., personalization is associated with perceived suffering). There were no significant differences in transportation between the personalized and nonpersonalized news stories $F_{(1,246)}=1.59, p=0.21$. Thus, $\mathrm{H} 4$ was not supported.

\section{Model Results}

Based on the aforementioned results, the hypothesized model was reduced to Figure 1 without associative SE and no direct association between story format and transportation. The final model fit the data well: $\chi^{2}(4)=29.0, p<0.000$, RMSEA (Root Mean Square Error of Approximation) $=0.035$, CFI (Comparative Fit Index) $=0.93$, and explained $87 \%$ of the variance in intention to donate (see Figure 2).

Story personalization was significantly associated with cognitive SE $(\beta=0.17, S E=0.06, p<0.01)$ and affective SE $(\beta=0.15, S E=0.07, p<0.05)(\mathrm{H} 1)$. Story personalization was also significantly associated with perceived suffering $(\beta=0.17$, $S E=0.06, p<0.01)(\mathrm{H} 2)$. The intensity of perceived suffering was positively associated with both the cognitive $(\beta=0.37, S E=$ $0.09, p<0.001)$ and affective dimensions of state empathy $(\beta=$ $0.24, S E=0.08, p<0.01$ ), providing support for $\mathrm{H} 3$.

Transportation was positively and significantly associated with perceived suffering $(\beta=0.56, S E=0.06, p<0.000)$, cognitive SE $(\beta=0.35, S E=0.08, p<0.000)$, and affective SE $(\beta=0.61, S E=0.06, p<0.000)$, providing support for $\mathrm{H} 5$.

H6 was supported. There was a significant association between affective SE and intentions to donate $(\beta=0.39, S E$ $=0.16, p<0.05)$. Cognitive SE, perceived suffering, and transportation were not directly associated with intentions to donate. This finding highlights the potential importance of affective responses to narrative stories as a critical pathway to promote prosocial intentions and provides limited support for the "cognitive hypothesis."

We used 1,000 bootstrap samples and bias-corrected confidence intervals to explore the specific indirect effects of transportation and perceived suffering on behavioral intentions. The specific indirect effects of transportation on donations, through affective $\mathrm{SE}$, are significant $(\beta=0.222, \mathrm{SE}=0.10, p=$ $0.025) 95 \%$ CI $[0.075,0.375]$.

\section{DISCUSSION}

News coverage about climate change, and the natural hazards associated with it, represent an opportunity that challenges 


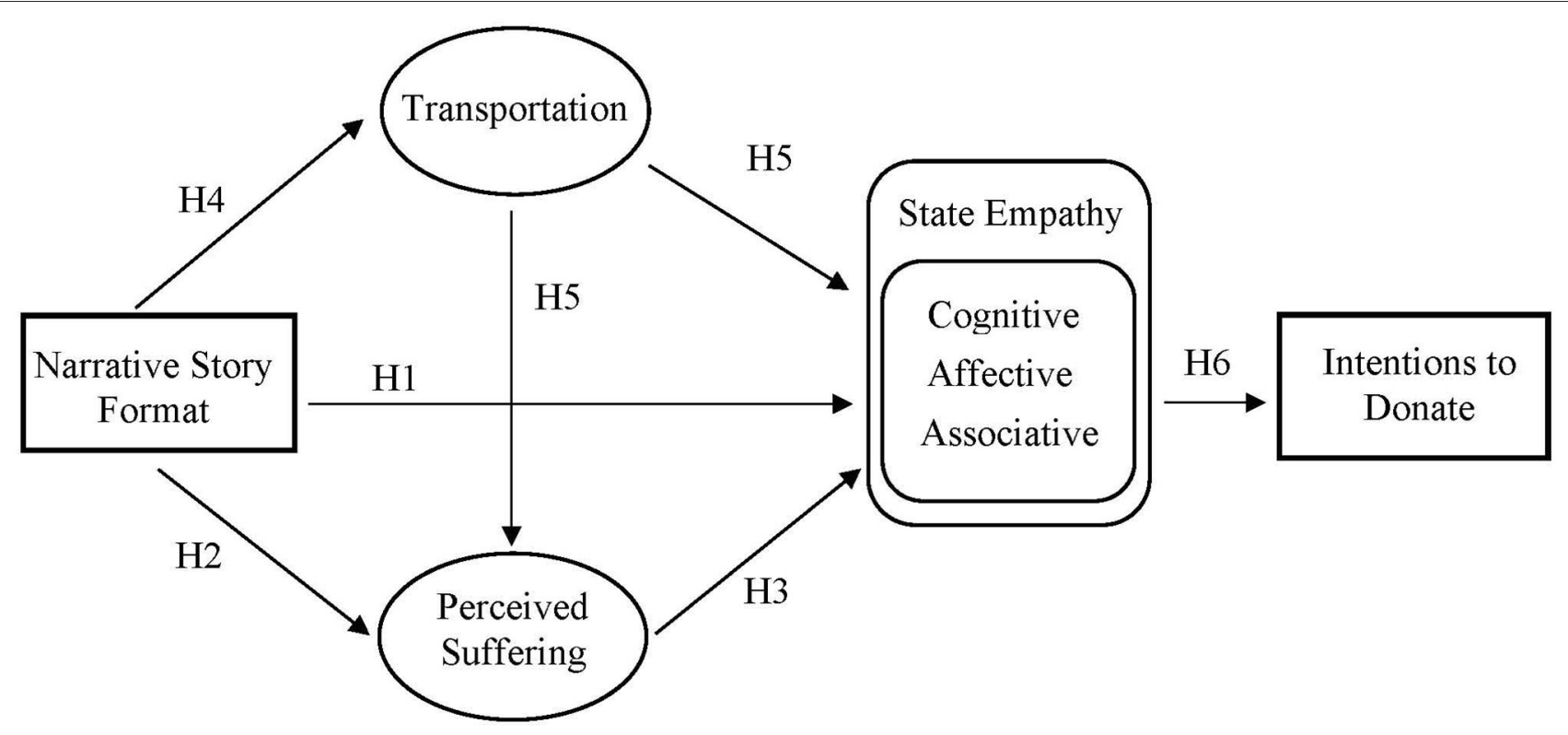

FIGURE 1 | Hypothesized model.

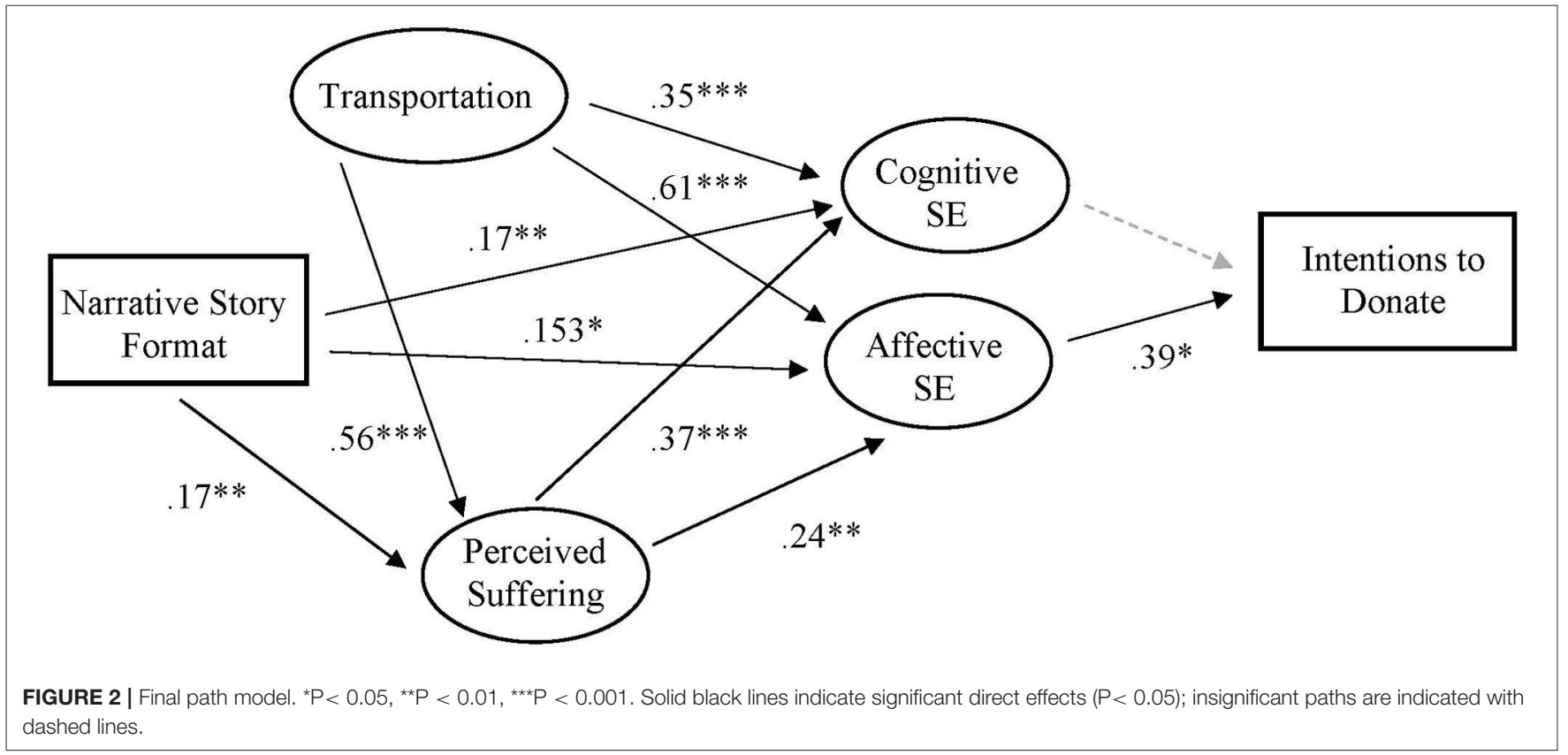

journalists' role as "critics of (nation) state power," tests journalism's "default position[s]," and demands "new ways of communicating” (Kunelius, 2019). This research sheds light on proposed patterns of causality between empathy-arousing messages and prosocial intentions and advances the use of empathy-arousing messages and emotional storytelling in the context of drought and natural hazards. This study's findings also illustrate the nuanced effects of state empathy on behavioral intentions and the importance of affective responses to narratives portraying human suffering. Overall, the expected relationships were observed in most cases, and the final model accounted for a large amount of the variance in respondents' intentions to donate to farmers suffering from drought.

Relative to participants exposed to the non-personalized news story, participants exposed to the personalized news story reported higher levels of perceived suffering, cognitive $\mathrm{SE}$, and affective SE, confirming and building on previous evidence that narrative news stories about environmental hazards can engender emotional responses from readers that may in turn encourage prosocial action. While previous research has 
suggested that identification (associative SE) is a key dimension of state empathy, we were not able to verify these findings because our stimuli did not generate a significant associative response. It is possible that this is due to the nature of the sample and a story focused on an adult farmer instead of a younger subject.

Perceived suffering was directly associated with the affective and cognitive dimensions of state empathy. While previous work has used perceived suffering as a criterion for the selection of empathy-arousing messages (Shen, 2011), this study empirically tested the role of perceived suffering in activating state empathy and prosocial intentions. Our findings highlight the importance of perceived suffering in state empathy arousal, but fail to provide evidence of a significant effect of perceived suffering on prosocial behaviors. While Maier et al. (2017) found that news stories about large-scale distant suffering were more effective in generating emotional responses (e.g., sympathy, sadness, anger), and indirectly, charitable giving, we only found partial support for these associations in the context of drought. It is possible that perceived suffering is not as strongly associated with helping behavior as actual emotional distress or transportation. Indeed, the observed significant indirect effects from transportation to intentions through affective SE would appear to support this assertion. It is also possible that the use of younger participants, less able to regulate emotions (Somerville et al., 2010), also contributed to these results. We discuss the limitations of using a student sample in detail below. These findings may also be due to the fact that this study emphasized the economic impacts of drought on farmers. Previous scholarship in agro-environmental contexts has found that economic messages have a more muted effect on public opinions than environmental messages (Peterson et al., 2019). Future work could explore alternative frames with varying degrees of emotional arousal.

Oliver et al. (2012) found differences in one of the two transportation measures (differences in story involvement but no differences in story impact) between the narrative and non-narrative story formats. In this study, we found a strong association between narrative engagement and perceived suffering and narrative engagement and state empathy. These results appear to confirm Oliver et al.'s (2012) assertation that narrative engagement precedes compassionate and affective responses to narrative stories.

Previous research has revealed inconsistent effects of story manipulation on transportation when readers were assigned specific reading goals (e.g., proofreading vs. regular reading) or when stories were labeled as fact or fiction (Gnambs et al., 2014). Shen et al. (2014) also reported mixed results with transportation: narrative stories with an environmental frame led to greater transportation, but stories with an economic frame revealed no increase in audience transportation. Our results indicating no direct effect between personalization and transportation align with these previous findings. Similarly, the personified story used in this study focused on farmers' economic losses. Given these results, it is possible that economic frames are less effective in generating transportation and future work should explore this option. While our study revealed no significant differences in transportation between a personalized and non-personalized story, personalization is only one form that strategic narratives can take (Zhou and Niederdeppe, 2017). Future work could also explore how narrative dramatization, emotionalization, and fictionalization might influence readers' emotional and prosocial responses to news coverage about natural hazards.

In this study, only affective state empathy was directly associated with intentions to donate. This finding reinforces previous evidence suggesting that affective empathy is more proximal to action than the cognitive dimension (Singer and Lamm, 2009). Moreover, these results suggest that the connection between empathy and prosocial intentions may only occur with the arousal of the affective dimension of empathy, providing one potential explanation for the previously mixed results exploring the empathy-arousing ability of narratives (Keen, 2007). These results suggest that the current empathy-altruism hypothesis could be modified to better account for differences in the effect of the cognitive, affective, and associative dimensions of state empathy on behavioral intentions.

\section{Limitations}

Participants were limited to students at a public university in the U.S. It is possible that participants with more direct experience with drought or farming would be more likely to identify with the individual profiled in the personalized news story. It is possible that lack of experience with drought contributed to the lack of an observed direct relationship between identification and prosocial behavior. In addition, students' limited ability to make a financial contribution might be another reason for the lack of direct effects of story type or perceived suffering on prosocial behavior. Finally, participants were recruited as part of a class on media and society. Thus, this population may be more sensitized to different modes of communication and thus less affected by the stimuli used in this study. We recommend that future research replicate this study with adults.

Additionally, our measure of readers' donations, which we used to test Hypothesis 6 and Research Question 1, assessed participants' general intention to donate money, rather than asking them to make an actual donation or to specify how much they would donate. Although research related to the Theory of Planned Behavior (Ajzen, 1991) suggests that individuals' behavioral intentions are often highly correlated with their actual behavior, assessing actual donations would have been preferable. Additionally, the yes/no format of the donation intentions question may have obscured differences between participants in the degree to which they planned to donate, or made them more likely to select the "yes" option (given it did not have a monetary value attached to it). Future research that enables participants to make actual donations of differing amounts would be a valuable next step.

Finally, the approach used in this study tells only how respondents felt immediately after reading personalized and nonpersonalized articles about drought. This approach provides us with limited information about the potential cumulative effect of mass media disaster coverage or the long-term impacts of reading a personalized news story about large-scale distant disasters.

In spite of these limitations, these findings suggest that personalized news stories about drought events are one potential pathway to encourage readers' emotional responses, including 
perceived suffering and state empathy. Our results also suggest that transportation into a story, perceived suffering and state empathy may interact in important ways to contribute to intentions to support individuals during drought events. While intentions are important, social action around drought, water scarcity, and climate change will require significantly more direct action, including political lobbying, organizing, and public protests. While we found many important relationships between our primary measures, we found no direct relationship between personalization and behavioral intentions. Thus, additional work is needed to further explore the effect of emotional storytelling on the adoption of prosocial actions in response to drought and natural hazards.

In addition, we add a note of caution about the use of personalized stories to motivate action. Prior evidence from a variety of studies in health communication suggests that personalized stories are effective in encouraging individual attitudes and behaviors. However, previous research has also highlighted the limitations of using personalized narratives to generate collective action or promote specific social policies. For example, compared to depersonalized formats, personalized narratives generated more counterarguments in response to claims that social factors drive obesity (Zhou and Niederdeppe, 2017) and less support for school-based nutrition policies (Barry et al., 2013). Moreover, given the potential for psychological reactance to messages about climate change (Dixon et al., 2019; Ma et al., 2019), messages about drought must be carefully designed and tested to avoid responses that might undermine effective persuasion (Nabi et al., 2018). Future scholarship should explore the potential for personalized narratives in environmental contexts to encourage both individual-level attitudes and behaviors as well as collective action and policy support.

Given the potential for the frequency, duration, and severity of drought events to increase, there is a critical need for further study about the use of emotional storytelling for hazard coverage. Our work focused on personalized and non-personalized news stories about farmers, but future work could explore empathic and prosocial responses to stories about other groups (i.e., the elderly, immigrants). Previous research has suggested that reports about floods by Western-dominated global media are less likely to use personal stories about individual suffering when reporting about flooding in the developing world (Solman and Henderson, 2019). Future work could explore if readers' empathic responses to stories about individual suffering vary by subject location, nationality, gender, and race.

The extreme suffering produced by drought highlights the importance of understanding how to mobilize an effective collective response to slow-onset hazards such as drought and water scarcity. One potential tool for such mobilization is the media. Yet while "just-the-facts" reporting about drought, environmental hazards, or climate change, may raise awareness about these environmental issues, emotive storytelling and personalized narratives appear to be a promising tool to generate readers' empathic responses and, indirectly, intentions to support individuals suffering due to drought. In addition, our findings suggest that personalized stories designed to produce prosocial intentions may be more effective when they generate a combination of transportation, perceived suffering, and affective state empathy. In sum, these results point to ways that environmental writers and reporters can raise awareness and potentially mobilize social action around drought and water scarcity.

\section{DATA AVAILABILITY STATEMENT}

The raw data supporting the conclusions of this article will be made available by the authors, without undue reservation.

\section{ETHICS STATEMENT}

The studies involving human participants were reviewed and approved by Institutional Review Board, Iowa State University Office of Research Ethics. Written informed consent for participation was not required for this study in accordance with the national legislation and the institutional requirements.

\section{AUTHOR CONTRIBUTIONS}

DW led the development of the research design, oversaw the analysis, research interpretation, and writing. EJ and NW assisted with the development of the survey, data interpretation, and writing. $\mathrm{JH}$ assisted with data interpretation and writing. All authors contributed to the article and approved the submitted version.

\section{FUNDING}

Funding for this effort was provided by the National Science Foundation under Grant No. AN-1530847. This work was also partially supported by the National Science Foundation under Grant No. SES-1462086, DMUU: DCDC III: Transformational Solutions for Urban Water Sustainability Transitions in the Colorado River Basin. Any opinions, findings and conclusions or recommendations expressed in this material are those of the author(s) and do not necessarily reflect the views of the National Science Foundation (NSF).

\section{ACKNOWLEDGMENTS}

The authors are thankful for support with survey development from E. Segal, C. Park, and S. Won. We are grateful to A. King for feedback on earlier versions of this manuscript. We would also like to thank all our participants for sharing their time and views.

\section{SUPPLEMENTARY MATERIAL}

The Supplementary Material for this article can be found online at: https://www.frontiersin.org/articles/10.3389/fcomm. 2020.588978/full\#supplementary-material 


\section{REFERENCES}

Aarøe, L. (2011). Investigating frame strength: the case of episodic and thematic frames. Polit. Commun. 28, 207-226. doi: 10.1080/10584609.2011.568041

Ajzen, I. (1991). The theory of planned behavior. Organizational behavior and human decision processes. Theor. Cogn. Self Regul. 50, 179-211. doi: 10.1016/0749-5978(91)90020-T

Appel, M., Gnambs,T., Richter, T., and Green, M. C. (2015). The Transportation Scale-Short Form (TS-SF). Med. Psychol. 18, 243-266. doi: $10.1080 / 15213269.2014 .987400$

Bagozzi, R. P., and Moore, D. J. (1994). Public service advertisements: emotions and empathy guide prosocial behavior. J. Mark. 58, 56-70. doi: $10.1177 / 002224299405800105$

Barry, C. L., Brescoll, V. L., and Gollust, S. E. (2013). Framing childhood obesity: how individualizing the problem affects public support for prevention. Polit. Psychol. 34, 327-349. doi: 10.1111/pops.12018

Batson, C. D. (1991). The Altruism Question: Toward a Social-Psychological Answer. Hillsdale, NJ: Lawrence Erlbaum Associates, Inc.

Batson, C. D. (2018). A Scientific Search for Altruism: Do We Care Only about Ourselves? Oxford University Press. Available online at: https://books.google. com/books?id=NWfmvQEACAAJ

Batson, C. D., Batson, J. G., Griffitt, C. A., Barrientos, S., Brandt, J. R., Sprengelmeyer, P., et al. (1989). Negative-state relief and the empathyaltruism hypothesis. J. Pers. Soc. Psychol. 56, 922-933. doi: 10.1037/0022-3514. 56.6 .922

Batson, C. D., Chang, J., Orr, R., and Rowland, J. (2002). Empathy, attitudes and action: can feeling for a member of a stigmatized group motivate one to help the group. Pers. Soc. Psychol. Bull. 28, 1656-1666. doi: 10.1177/014616702237647

Batson, C. D., Early, S., and Salvarani, G. (1997a). Perspective taking: imagining how another feels versus imagining how you would feel. Pers. Soc. Psychol. Bull. 23, 751-758. doi: 10.1177/0146167297237008

Batson, C. D., Polycarpou, M. P., Harmon-Jones, E., Imhoff, H. J., Mitchener, E. C., Bednar, L. L., et al. (1997b). Empathy and attitudes: can feeling for a member of a stigmatized group improve feelings toward the group? J. Pers. Soc. Psychol. 72, 105-118. doi: 10.1037/0022-3514.72.1.105

Beckett, C., and Deuze, M. (2016). On the role of emotion in the future of journalism. Soc. Med. Soc. 2:205630511666239. doi: $10.1177 / 2056305116662395$

Berenguer, J. (2007). The effect of empathy in proenvironmental attitudes and behaviors. Environ. Behav. 39, 269-283. doi: 10.1177/0013916506 292937

Berenguer, J. (2010). The effect of empathy in environmental moral reasoning. Environ. Behav 42, 110-134. doi: 10.1177/0013916508325892

Boltanski, L. (1999). Distant Suffering. Cambridge: Cambridge University Press. doi: $10.1017 /$ СBO9780511489402

Burke, K. (1969). A Rhetoric of Motives. Berkeley, CA: University of California Press.

Busselle, R., and Bilandzic, H. (2009). Measuring narrative engagement. Med. Psychol. 12, 321-347. doi: 10.1080/15213260903287259

Campbell, R. G., and Babrow, A. S. (2004). The role of empathy in responses to persuasive risk communication: overcoming resistance to HIV prevention messages. Health Commun. 16, 159-182. doi: 10.1207/S15327027HC1602_2

Church, S. P., Bentlage, B., Weiner, R., Babin, N., Bulla, B. R., Fagan, K., et al. (2020). National print media vs. agricultural trade publications: communicating the 2012 Midwestern US drought. Clim. Change 161, 43-63. doi: 10.1007/s10584-019-02630-3

Cialdini, R. B., Brown, S. L., Lewis, B. P., Luce, C., and Neuberg, S. L. (1997). Reinterpreting the empathy-altruism relationship: when one into one equals oneness. J. Pers. Soc. Psychol. 73, 481-494. doi: 10.1037/0022-3514.7 3.3.481

Cook, E. R., Seager, R., Cane, M. A., and Stahle, D. W. (2007). North American drought: reconstructions, causes, and consequences. Earth Sci. Rev. 81, 93-134. doi: 10.1016/j.earscirev.2006.12.002

Dahlstrom, M. F. (2014). Using narratives and storytelling to communicate science with nonexpert audiences. Proc. Natl. Acad. Sci. U.S.A. 111 (Suppl. 4), 13614-13620. doi: 10.1073/pnas.1320645111

Davis, M. H. (1994). Empathy: A Social Psychological Approach. Boulder, CO: Westview Press.
Decety, J., and Jackson, P. L. (2006). A social-neuroscience perspective on empathy. Curr. Dir. Psychol. Sci. 15, 54-58. doi: 10.1111/j.0963-7214.2006.00406.x

Decety, J., and Lamm, C. (2006). Human empathy through the lens of social neuroscience. Sci. World J. 6, 1146-1163. doi: 10.1100/tsw.2006.221

Dillow, M. R., and Weber, K. (2016). An experimental investigation of social identification on college student organ donor decisions. Commun. Res. Rep. 33, 239-246. doi: 10.1080/08824096.2016.1186630

Dixon, G., Hmielowski, J., and Ma, Y. (2019). More evidence of psychological reactance to consensus messaging: a response to van Der Linden, Maibach, and Leiserowitz (2019). Environ. Commun. 1-7. doi: $10.1080 / 17524032.2019 .1671472$

Duffy, K. (2016). Setting the Drought Agenda: A Comparative Study of Local and National Newspaper Coverage of the California Drought, 2013-2015. Order No. 10158112. State University. 1839342755. SciTech Premium Collection. Available online at: https://search.proquest.com/docview/1839342755?pqorigsite $=$ gscholar

Eisenberg, N., and Miller, P. (1987). The relation of empathy to prosocial and related behaviors. Psychol. Bull. 101, 91-119. doi: 10.1037/0033-2909.101.1.91

Finlay, K., and Stephan, W. G. (2000). Improving intergroup relations: the effects of empathy on racial attitudes. J. Appl. Soc. Psychol. 30, 1720-1737. doi: 10.1111/j.1559-1816.2000.tb02464.x

Gerdes, K. E., Lietz, C. A., and Segal, E. A. (2011). Measuring empathy in the 21st century: development of an empathy index rooted in social cognitive neuroscience and social justice. Soc. Work Res. 35, 83-93. doi: $10.1093 / \mathrm{swr} / 35.2 .83$

Gerdes, K. E., Segal, E., and Lietz, C. (2010). Conceptualising and measuring empathy. Br. J. Soc. Work 40, 2326-2343. doi: 10.1093/bjsw/bcq048

Gerdes, K. E., and Segal, E. A. (2009). A social work model of empathy. Adv. Soc. Work 10, 114-127. doi: 10.18060/235

Gnambs, T., Appel, M., Schreiner, C., Richter, T., and Isberner, M.-B. (2014). Experiencing narrative worlds: a latent state-trait analysis. Pers. Individ. Dif. 69, 187-192. doi: 10.1016/j.paid.2014.05.034

Grant, A. M., and Berry, J. W. (2011). The necessity of others is the mother of invention: intrinsic and prosocial motivations, perspective taking, and creativity. Acad. Manage. J. 54, 73-96. doi: 10.5465/amj.2011.59215085

Green, M. C. (2006). Narratives and cancer communication. J. Commun. 56, S163-S183. doi: 10.1111/j.1460-2466.2006.00288.x

Green, M. C., and Brock, T. C. (2000). The role of transportation in the persuasiveness of public narratives. J. Personal. Soc. Psychol. 79, 701-721. doi: 10.1037/0022-3514.79.5.701

Green, M. C., Brock, T. C., and Kaufman, G. F. (2004). Understanding media enjoyment: the role of transportation into narrative worlds. Commun. Theor. 14, 311-327. doi: 10.1111/j.1468-2885.2004.tb00317.x

Hoffman, M. L. (1981). Is altruism part of human nature? J. Pers. Soc. Psychol. 40, 121-137. doi: 10.1037/0022-3514.40.1.121

Houston, J. B., Pfefferbaum, B., and Rosenholtz, C. E. (2012). Disaster news: framing and frame changing in coverage of major U.S. natural disasters, 2000-2010. J Mass Commun. Q. 89, 606-623. doi: 10.1177/1077699012456022

Hu, L., and Bentler, P. M. (1999). Cutoff criteria for fit indexes in covariance structure analysis: conventional criteria versus new alternatives. Struct. Equat. Model. 6, 1-55. doi: 10.1080/10705519909540118

Iacoboni, M. (2008). Mirroring People: The New Science of How We Connect with Others, 1 st Edn. New York, NY: Farrar, Straus and Giroux.

Joye, S. (2015). Domesticating distant suffering: how can news media discursively invite the audience to care? Int. Commun. Gazette 77, 682-694. doi: $10.1177 / 1748048515601560$

Keen, S. (2007). Empathy and the Novel. New York, NY: Oxford University Press.

Keen, S. (2010). "Narrative empathy," in Toward a Cognitive Theory of Narrative Acts, ed F. L. Aldama (Austin, TX: University of Texas Press), 61-93.

Kim, H. S., Bigman, C. A., Leader, A. E., Lerman, C., and Cappella, J. N. (2012). Narrative health communication and behavior change: the influence of exemplars in the news on intention to quit smoking. J. Commun. 62, 473-492. doi: 10.1111/j.1460-2466.2012.01644.x

Kim, M.-S., and Hunter, J. E. (1993). Relationships among attitudes, behavioral intentions, and behavior: a meta-analysis of past research, part 2. Commun. Res. 20, 331-364. doi: 10.1177/009365093020003001

Kogut, T., and Ritov, I. (2005). The 'identified victim' effect: an identified group, or just a single individual? J. Behav. Decis. Mak. 18, 157-167. doi: 10.1002/bdm.492 
Kreuter, M. W., Green, M. C., Cappella, J. N., Slater, M. D., Wise, M. E., Storey, D., et al. (2007). Narrative communication in cancer prevention and control: a framework to guide research and application. Ann. Behav. Med. 33, 221-235. doi: 10.1007/BF02879904

Kunelius, R. (2019). A forced opportunity: climate change and journalism. Journalism 20, 218-221. doi: 10.1177/1464884918807596

Ma, Y., Dixon, G., and Hmielowski, J. D. (2019). Psychological reactance from reading basic facts on climate change: the role of prior views and political identification. Environ. Commun. 13, 71-86. doi: 10.1080/17524032.2018.1548369

Maier, S. R., Slovic, P., and Mayorga, M. (2017). Reader reaction to news of mass suffering: assessing the influence of story form and emotional response. J. Theor. Pract. Crit. 18, 1011-1029. doi: 10.1177/1464884916663597

Matsunaga, M. (2010). How to factor-analyze your data right: Do's, don'ts, and How-To's. Int. J. Psychol. Res. 3, 97-110.

Miaskiewicz, T., and Monarchi, D. E. (2008). A review of the literature on the empathy construct using cluster analysis. Commun. Assoc. Inform. Syst. 22, 117-142. doi: 10.17705/1CAIS.02207

Mishra, A. K., and Singh, V. P. (2010). A review of drought concepts. J. Hydrol. 391, 202-216. doi: 10.1016/j.jhydrol.2010.07.012

Müller, B. C. N., Maaskant, A. J., Van Baaren, R. B., and Dijksterhuis, A. P. (2012). Prosocial consequences of imitation. Psychol. Rep. 110, 891-898. doi: 10.2466/07.09.21.PR0.110.3.891-898

Murphy, S. T., Frank, L. B., Chatterjee, J. S., and Baezconde-Garbanati, L. (2013). Narrative versus nonnarrative: the role of identification, transportation, and emotion in reducing health disparities: narrative vs. nonnarrative. J. Commun. 63, 116-137. doi: 10.1111/jcom.12007

Muthén, L. K., and Muthén, B. O. (1998). Mplus User's Guide, 8th Edn. Los Angeles, CA: Muthén and Muthén.

Nabi, R. L., Gustafson, A., and Jensen, R. (2018). Framing climate change: exploring the role of emotion in generating advocacy behavior. Sci. Commun. 40, 442-468. doi: 10.1177/1075547018776019

Nunnally, J. C. (1978). Psychometric Theory. New York, NY: McGraw-Hill.

O'Keefe, D. J. (2003). Message properties, mediating states, and manipulation checks: claims, evidence, and data analysis in experimental persuasive message effects research. Commun. Theor. 13, 251-274. doi: 10.1111/j.1468-2885.2003.tb00292.x

Oliver, M. B., Dillard, J. P., Bae, K., and Tamul, D. J. (2012). The effect of narrative news format on empathy for stigmatized groups. J. Mass Commun. Q. 89, 205-224. doi: 10.1177/1077699012439020

Papacharissi, Z., and de Fatima Oliveira, M. (2012). Affective news and networked publics: the rhythms of news storytelling on \#Egypt. J. Commun. 62, 266-282. doi: 10.1111/j.1460-2466.2012.01630.x

Peterson, D. A. M., Carter, K. C., Wald, D. M., Gustafson, W., Hartz, S., Donahue, J., et al. (2019). Carbon or cash: evaluating the effectiveness of environmental and economic messages on attitudes about wind energy in the United States. Energy Res. Soc. Sci. 51, 119-128. doi: 10.1016/j.erss.2019.01.007

Preston, S. D., and de Waal, F. B. M. (2002). Empathy: its ultimate and proximate bases. Behav. Brain Sci. 25, 1-20; discussion 20-71. doi: 10.1017/S0140525X02000018

Schultz, P. W. (2000). Empathizing with nature: the effects of perspective taking on concern for environmental issues. J. Soc. Issues 56, 391-406. doi: 10.1111/0022-4537.00174

Segal, E. A., Gerdes, K. E., Leitz, C., Wagaman, M. A., and Geiger, J. (2017). Assessing Empathy. New York, NY: Columbia University Press. doi: 10.7312/kehr18115

Segal, E. A., Wagaman, M. A., and Gerdes, K. E. (2012). Developing the social empathy index: an exploratory factor analysis. Adv. Soc. Work 13, 541-560. doi: $10.18060 / 2042$

Shelton, M. L., and Rogers, R. W. (1981). Fear-arousing and empathy-arousing appeals to help: the pathos of persuasion. J. Appl. Soc. Psychol. 11, 366-378. doi: 10.1111/j.1559-1816.1981.tb00829.x
Shen, F., Ahern, L., and Baker, M. (2014). Stories that count: influence of news narratives on issue attitudes. J. Mass Commun. Q. 91, 98-117. doi: 10.1177/1077699013514414

Shen, L. (2010a). Mitigating psychological reactance: the role of messageinduced empathy in persuasion. Hum. Commun. Res. 36, 397-422. doi: 10.1111/j.1468-2958.2010.01381.x

Shen, L. (2010b). On a scale of state empathy during message processing. Western J. Commun. 74, 504-524. doi: 10.1080/10570314.2010.512278

Shen, L. (2011). The effectiveness of empathy versus fear arousing antismoking PSAs. Health Commun. 26, 401-415. doi: 10.1080/10410236.2011. 552480

Singer, T., and Lamm, C. (2009). The social neuroscience of empathy. Ann. N. Y. Acad. Sci. 1156, 81-96. doi: 10.1111/j.1749-6632.2009. 04418.x

Slater, M. D., and Rouner, D. (2002). Entertainment-education and elaboration likelihood: understanding the processing of narrative persuasion. Commun. Theor. 12, 173-191. doi: 10.1111/j.1468-2885.2002.tb0 0265.x

Solman, P., and Henderson, L. (2019). Flood disasters in the United Kingdom and India: a critical discourse analysis of media reporting. Journalism 20, 1648-1664. doi: 10.1177/1464884918762363

Somerville, L. H., Jones, R. M., and Casey, B. J. (2010). A time of change: behavioral and neural correlates of adolescent sensitivity to appetitive and aversive environmental cues. Brain Cogn. Adolesc. Brain Dev. Curr. Themes Future Dir. 72, 124-133. doi: 10.1016/j.bandc.2009.07.003

Stephan, W. G., and Finlay, K. (1999). The role of empathy in improving intergroup relations. J. Soc. Issues 55, 729-743. doi: 10.1111/0022-4537. 00144

Stiff, J. B., Dillard, J. P., Somera, L., Kim, H., and Sleight, C. (1988). Empathy, communication, and prosocial behavior. Commun. Monogr. 55, 198-213. doi: 10.1080/03637758809376166

Swim, J. K., and Bloodhart, B. (2015). Portraying the perils to polar bears: the role of empathic and objective perspective-taking toward animals in climate change communication. Environ. Commun. 9, 446-468. doi: 10.1080/17524032.2014.987304

van Baaren, R., Janssen, L., Chartrand, T. L., and Dijksterhuis, A. (2009). Where is the love? The social aspects of mimicry. Philos. Trans. R. Soc. Lond. Ser. B Biol. Sci. 364, 2381-2389. doi: 10.1098/rstb.2009.0057

Wahl-Jorgensen, K. (2013). The strategic ritual of emotionality: a case study of pulitzer prize-winning articles. J. Theor. Pract. Crit. 14, 129-145. doi: $10.1177 / 1464884912448918$

Wilhite, D. A., Sivakumar, M. V. K., and Pulwarty, R. (2014). Managing drought risk in a changing climate: the role of national drought policy. Weather Clim. Extremes 3, 4-13. doi: 10.1016/j.wace.2014.01.002

Wilson, K. M. (2000). Drought, debate, and uncertainty: measuring reporters' knowledge and ignorance about climate change. Public Understand. Sci. 9, 1-13. doi: 10.1088/0963-6625/9/1/301

Zhou, S., and Niederdeppe, J. (2017). The promises and pitfalls of personalization in narratives to promote social change. Commun. Monogr. 84, 319-342. doi: $10.1080 / 03637751.2016 .1246348$

Conflict of Interest: The authors declare that the research was conducted in the absence of any commercial or financial relationships that could be construed as a potential conflict of interest.

Copyright (c) 2021 Wald, Johnston, Wellman and Harlow. This is an open-access article distributed under the terms of the Creative Commons Attribution License (CC $B Y)$. The use, distribution or reproduction in other forums is permitted, provided the original author(s) and the copyright owner(s) are credited and that the original publication in this journal is cited, in accordance with accepted academic practice. No use, distribution or reproduction is permitted which does not comply with these terms. 